\title{
Identifying fundamental criteria for eating disorder recovery: a systematic review and qualitative meta-analysis
}

\author{
Jan Alexander de $\operatorname{Vos}^{1,2^{*}}$ (D), Andrea LaMarre ${ }^{3}$, Mirjam Radstaak' Charlotte Ariane Bijkerk², Ernst T. Bohlmeijer ${ }^{1,4}$ \\ and Gerben J. Westerhof ${ }^{1}$
}

\begin{abstract}
Background: Outcome studies for eating disorders regularly measure pathology change or remission as the only outcome. Researchers, patients and recovered individuals highlight the importance of using additional criteria for measuring eating disorder recovery. There is no clear consensus on which additional criteria are most fundamental. Studies focusing on the perspectives of recovered patients show criteria which are closely related to dimensions of positive functioning as conceptualized in the complete mental health model. The aim of this study was to identify fundamental criteria for eating disorder recovery according to recovered individuals.
\end{abstract}

Methods: A systematic review and a qualitative meta-analytic approach were used. Eighteen studies with recovered individuals and meeting various quality criteria were included. The result sections of the included papers were searched for themes that were stated as criteria for recovery or 'being recovered'. All themes were analyzed using a meta-summary technique. Themes were labeled into criteria for recovery and the frequency of the found criteria was examined.

Results: In addition to the remission of eating disorder pathology, dimensions of psychological well-being and selfadaptability/resilience were found to be fundamental criteria for eating disorder recovery. The most frequently mentioned criteria were: self-acceptance, positive relationships, personal growth, decrease in eating disorder behavior/cognitions, self-adaptability/resilience and autonomy.

Conclusions: People who have recovered rate psychological well-being as a central criterion for ED recovery in addition to the remission of eating disorder symptoms. Supplementary criteria, besides symptom remission, are needed to measure recovery. We recommend including measurements of psychological well-being and self-adaptability/resilience in future research, such as outcome studies and in routine outcome measurement.

Keywords: Eating disorders, Recovery, Psychopathology, Psychological well-being, Positive mental health, Meta-analysis, Qualitative research, Systematic review, Positive psychology

\section{Plain English summary}

In this study, we examined the perspective on criteria for eating disorder recovery among recovered patients. We searched in scientific databases for all published qualitative studies on eating disorder recovery. Eighteen studies were included after meeting rigorous inclusion criteria. The results sections of these studies were

\footnotetext{
* Correspondence: s.devos@humanconcern.nl

${ }^{1}$ Centre for eHealth and Well-being Research, University of Twente,

Psychology, Health, \& Technology, Enschede, The Netherlands

${ }^{2}$ Human Concern Foundation, center for Eating Disorders, Amsterdam, The

Netherlands

Full list of author information is available at the end of the article
}

analyzed by extracting relevant themes for eating disorder recovery. After calculating effect sizes for the criteria, we found high effect sizes for: self-acceptance, positive relations with others, personal growth, eating disorder remission, self-adaptability, and autonomy, indicating that these are important criteria according to recovered individuals. In addition to the remission of the eating disorder symptoms, dimensions of psychological well-being and self-adaptability/resilience are found as important criteria for eating disorder recovery. This study, among others, shows relevant criteria for eating 
disorder recovery in addition to the remission of eating disorder symptoms.

\section{Background}

Eating disorders (EDs) are serious mental disorders that impact all facets of people's lives, including quality of life at home and work, personal functioning, and social life [1-3]. Anorexia Nervosa (AN) has the highest mortality rate of all mental illnesses $[4,5]$. Eating disorders are often chronic and refractory [6].

In the last decade, clinical guidelines have been established with treatment options based on evidence (evidence-based care) [7-9]. These treatment options, however, work only for a percentage of patients; for AN in particular, there is no single superior treatment option [10-12]. Effectiveness and efficacy studies, herein called outcome studies, are critical for establishing guidelines for evidence-based care. Outcome studies use measures to examine which treatments are effective, based on the degree of recovery from an ED on certain criteria. There is significant disagreement in the field around the definition of ED recovery, and the relevant criteria that must be present in order to claim "recovery"; see for instance McGilley \& Szablewski for an overview [13-18]. As a result, rates of recovery within outcome studies vary widely, ranging from $3 \%$ to $96 \%$ depending on the criteria used [19]. Recovery is usually measured as the remission of ED symptoms [20]. In a systematic review of 119 patient outcome studies on AN, Steinhausen [20] concluded that remission from all essential clinical symptoms could be considered as recovery; however, he also noted substantial variation in outcome criteria between studies. In a systematic review of predictors of ED outcomes by Vall and Wade [21], over $80 \%$ of the 126 included studies reported outcomes based solely on symptom remission [21]. Commonly-used measures were: frequency or absence of binging/purging, change or reaching cut off scores on a questionnaire/interview for measuring ED symptoms (Fairburn \& Beglin [22]), changes or remission from overall ED symptoms, or change in BMI or reaching a specific cut off point [21]. In sum, outcome studies generally frame recovery around clinically relevant changes in ED symptoms, or remission.

Simultaneously, a growing body of literature in the ED field highlights that ED symptom change (remission) is not sufficient for understanding, capturing and measuring ED recovery and emphasizes the importance of additional criteria, related to (mental) health, such as quality of life, well-being, psychological, social and emotional functioning [16, 23-26]. This study aims to identify fundamental criteria for recovery from eating disorders focusing on criteria related to clinical symptoms and additional criteria, related to mental health and well-being.

\section{Mental health: the important role of well-being}

Psychologists have lobbied for decades to convey that health is not merely the absence of disease (i.e. symptoms), but also the presence of something positive [27-34]. The emergence of positive psychology, for example, is based on re-focusing the exclusive attention on absence of pathology as a marker for health only, to positive aspects of mental and social functioning as markers for well-being as well [30]. This is in line with the declaration of the World Health Organization (WHO) on mental health: 'a state of well-being in which the individual realizes his or her own abilities, can cope with the normal stresses of life, can work productively and fruitfully, and is able to make a contribution to his or her community' (p. 12 [35]). Keyes [36] proposed the 'complete mental health model', based on this definition, taking both the absence of psychopathology and the presence of well-being as two related but different aspects of health into account. He did not define health and well-being as a fixed state, but operationalized it as a syndrome consisting of several criteria, where upon people can develop, meeting certain thresholds for optimal well-being [37].

Well-being is theoretically divided into psychological, emotional and social well-being [31, 37, 38]. Psychological well-being (PWB) was conceptualized by Ryff [38] and consists of six key dimensions: self-acceptance, autonomy, environmental mastery, purpose and meaning in life, personal growth and positive relationships with others [34, 38]. This is the model used when we refer to PWB throughout this article. Emotional well-being includes happiness, positive affect and avowed life satisfaction. Social well-being encompasses social contribution, integration, actualization, acceptance and coherence [36]; see for instance [38-40] for an overview of wellbeing and its theoretical and philosophical background. Recent studies show that psychopathology and wellbeing are separate but complementary aspects of mental health and reflect two related continua, instead of being opposites on one continuum [29, 37, 40]. In addition, a bi-directional relationship between psychopathology and positive mental health over time is found [41].

The complete mental health model emphasizes the importance of positive functioning for mental health, however, this is widely neglected in research on eating disorders [42]. While several studies have focused on positive mental health in terms of quality of life or subjective well-being, only one study examined all PWB dimensions among eating disorder patients [1, 3, 23, 42-44]. In the study that examined PWB, the authors found that ED patients had impaired PWB compared to a control group [42]. Also, these studies examined the presence of PWB among eating disorder patients, it has not been examined as a criterion for recovery. 
In qualitative research examining recovery criteria from eating disorders, there are many recovery themes that are related to the dimensions for well-being. Bowlby and Anderson [45], for instance, found several themes for recovery in a sample of therapists who were recovered from an eating disorder. Most of these themes matched the descriptions of the well-being dimensions. For example, the themes 'learning to understand and value the self' matches with the well-being dimensions "personal growth" and "self-acceptance", the theme "finding purpose and meaning in life" matches with the dimension "purpose" and the theme "developing healthy and meaningful relationships" matches with "positive relationships with others". In a survey examining criteria for recovery from eating disorders, Noordenbos and Seubring [25] found high consensus between ex-patients and clinicians on all of the proposed 52 statements, divided into five themes: eating behavior, physical, psychological, emotional, and social functioning. However, patients labeled self-esteem, a positive body attitude and expressing emotions as more important, while therapists accentuated eating behavior and physical recovery [25]. Emanuelli and colleagues [26] replicated this study in a sample of patients and clinicians, and concluded that recovery included general criteria (e.g. social, psychological, and emotional) and specific eating disorder criteria (e.g. weight controlling behaviors and evaluation of one's appearance) [26]. Patients and clinicians agreed on the ranking of importance of most criteria, but patients considered "psychological, emotional, social" and "evaluation of one's own appearance" criteria as more important for recovery than did clinicians. The researchers did not find weight and weight gain as central criteria for defining recovery [26]. Dawson, Rhodes and Touyz [24] used a different approach, and conducted an extensive Delphi study with ED professionals to determine criteria for recovery from Anorexia Nervosa (AN). They also concluded that, in addition to the minimal criteria (i.e., weight restoration and symptom reduction), psychological and quality of life measures should be part of the definition for AN recovery.

While these studies show the importance of additional criteria, they have several limitations, making it difficult to understand which criteria are most fundamental besides the ED pathology based criteria (remission). Noordenbos and Seubring [25] and Emmanuelli and colleagues [26] used a pre-fixed set of statements, making their study susceptible to missing criteria which might have been endorsed by ex-patients or clinicians had they been articulated in the design of the study. Several qualitative studies show criteria for recovery that were not present in the consensus studies with the prefixed statements [25, 26], such as improved selfacceptance, identity development, feelings of purpose and meaning in life, self-management and empowerment [45-47]. Other studies only focused on AN or did not take the perspective of recovered individuals into account. The importance of exploring the perspectives of those with lived experience on their recovery cannot be understated in this regard. Studies have shown that the orientation of patients towards recovery can change over time and during treatment $[48,49]$.

In conclusion, outcome studies tend to follow criteria for recovery that are based on changes in ED symptoms (remission), rather than aiming to ascertain health and well-being. It remains inconclusive which recovery criteria should be considered as fundamental. We argue that knowledge from individuals who have recovered from an ED should be leading and incorporated into the establishment of fundamental criteria for recovery. Qualitative studies examining the personal experience from recovered individuals highlight the importance of taking additional recovery criteria into account, which are closely related to the dimensions of well-being. However, the results of these qualitative studies have never been systematically reviewed. Responding to this knowledge gap, we carried out a systematic review and metaanalysis of existing qualitative studies of ED recovery.

The aim of this study is to identify fundamental criteria for recovery according to recovered individuals by performing a qualitative meta-analysis. Qualitative metaanalysis can be explained as the aggregation of studies to discover the essential elements of a phenomenon, and translating these results into a more comprehensive description or clear end-product [50,51]. An integrative interpretation of findings from multiple qualitative studies is therefore more substantive than those resulting from individual investigations [50, 52]. To our knowledge, this is the first study to use a qualitative metaanalysis to further identify fundamental criteria for ED recovery over all ED types, among people who were considered recovered.

\section{Method}

\section{Search strategy and selection of studies}

Guidelines from the PRISMA statement for reporting systematic reviews were used for the search strategy [53]. The first step was to perform a systematic search in two electronic databases, Medline and PsycInfo (final search date 04-02-2016). Terms were searched within all fields. There was no limitation for the year in which the study was published. The main search terms were (Recovery OR Recovered) AND (Eating Disorders OR Anorexia Nervosa OR Bulimia Nervosa OR Binge Eating Disorder) AND (Qualitative), resulting in 238 hits from PubMed and 403 hits from PsycInfo (with a subselection "qualitative studies").The second step was an additional search in which the reference list of two comprehensive 
qualitative studies of eating disorder recovery [45, 46] were screened. The third step was to screen all articles in the Google Scholar search engine that had cited [45, 46] (search date: 06-02-2016). Duplicates were removed as follows: 103 duplicates between PsycInfo and PubMed, 5 duplicates between study [45] and [46] and 49 duplicates between the first (PsycInfo and PubMed) and the additional search. In total 630 unique studies remained for screening.

The inclusion criteria were studies that 1) reported on the processes or criteria for eating disorder recovery, 2) included recovered individuals, either because they considered themselves to be recovered, and/or the study used a rigorous system to assess recovery, 3) used a qualitative study design, 4) were published in a peerreviewed journal or edited academic book, and 5) had a rigorous system for ensuring the credibility of dataanalysis (i.e. meeting the CASP protocol, see Procedure and analysis). All ED types as defined in the DSM5 [54] were included, since we were interested in overall criteria for recovery for ED patients. Studies which only or primarily included patients who were not considered recovered were excluded, as we were interested in understanding the markers or criteria for recovery, as opposed to future perspectives on recovery from those actively experiencing eating disorders. Unpublished reports and dissertations were not included to avoid studies that have not been peer-reviewed for quality and also to ensure that studies were not duplicating results [55].

The first and second author screened all eligible studies separately in two phases. In the first phase, selection was based on title and abstract. In the second phase, all selected articles were independently screened by the first two authors based on full text. Inter-rater agreement (kappa coefficient) between authors in the second round of screening was 0.81 (95\% CI .68-.91). When there was no agreement, the first two authors discussed decisions to include or exclude studies until agreement was reached. Finally, the reference lists of the included studies were cross-checked on eligible studies. This did not result in extra studies. In total 18 studies were included in the meta-analysis (see Fig. 1).

\section{Procedure and analysis}

A qualitative meta-analysis requires both 1) an assessment of the quality of the studies (i.e. the influence of the method of investigation on the findings) and, 2) results of a more comprehensive explanation of a phenomenon, including its ambiguities and differences found in the primary studies [50].

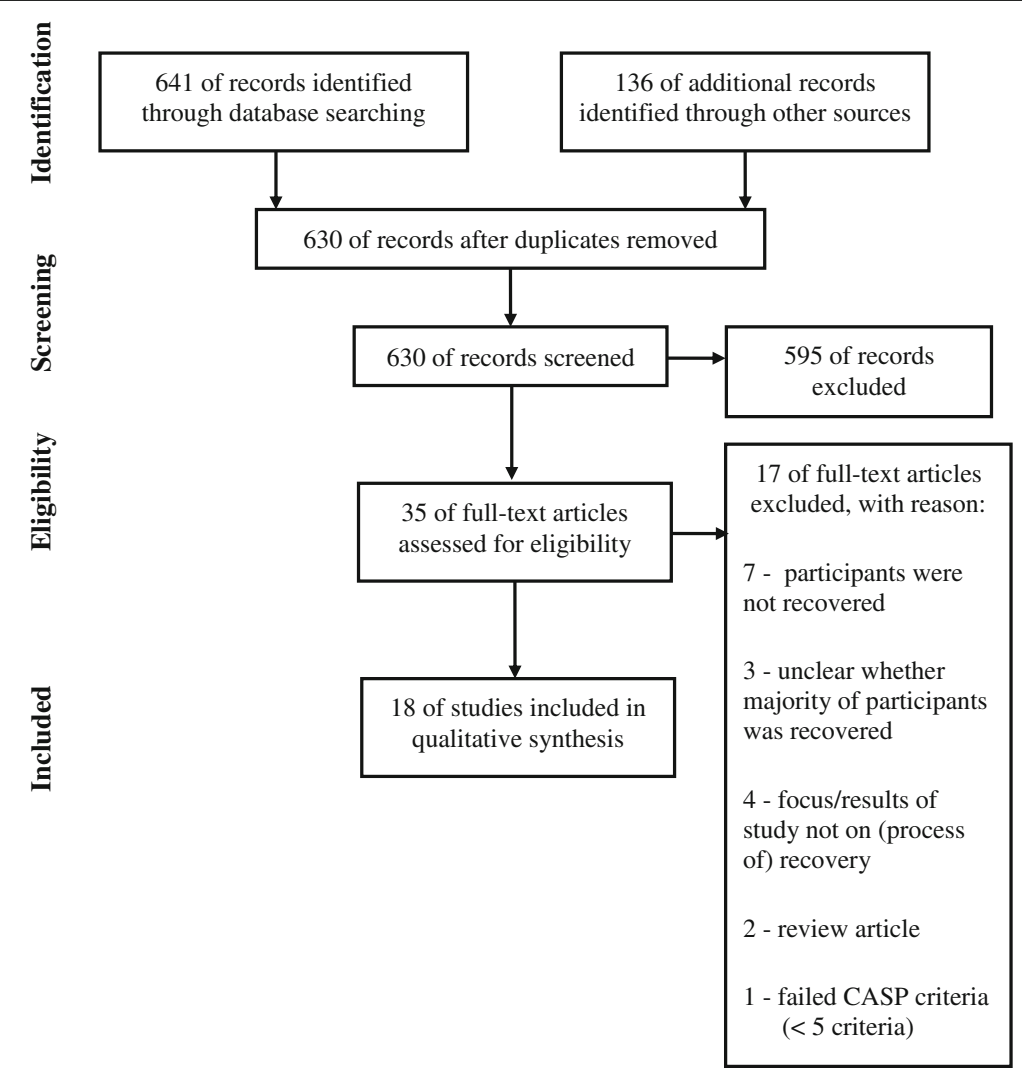

Fig. 1 Prisma diagram of study selection 


\section{Assessment of the quality of the studies}

For the first requirement the Critical Appraisal Skills Programme (CASP) [56] in addition to a complementary rating, was used. The CASP method is a standardized tool to help researchers to systematically examine qualitative studies. CASP is a commonly used method within qualitative meta-analysis, or -synthesis studies to assess credibility, value and relevance of the selected studies [47, 57-59]. In accordance with the CASP method and study [47], the quality of the studies was assessed on 10 themes, and classified as "A", low risk of bias (studies meeting 9 or 10 of the questions) or "B" moderate risk of bias (studies meeting at least 5 of the questions, but not more then 8). CASP method applies the following 10 criteria: 1 ) a clear statement of the aims, 2) methodological design is adequate to aims, 3) research design is appropriate to address aims, 4) recruitment strategy is appropriate to aims, 5) data collection in a way that addresses research issue, 6) relationship between researcher and participant is considered, 7) ethical issues are considered, 8) sufficiently rigorous analysis, 9) clear statement of findings, 10) importance of research. Besides the CASP method, a complementary rating for checking credibility was used by dividing studies in "A", low risk of bias (participants were recovered/in recovery for at least 2 years and recovery was at least selfreported), and "B" moderate risk of bias (participants were recovered/in recovery for less than 2 years, or it was unclear how long participants were recovered and/ or it was unclear whether recovery was self-reported). Combining both ratings resulted in 4 possible categories: 1) "A/A", low risk of bias, 2) "A/B" and, 3) "B/A", moderate risk of bias, and 4) " $\mathrm{B} / \mathrm{B}$ " substantial risk of bias.

\section{Analysis of criteria for recovery}

For the second requirement, a meta summary technique described by Sandelowski \& Barroso [60] was used. In contrast to meta-synthesis analysis, this method allows for extracting themes and an evaluation of their frequencies [50,60]. The following strategy was used: 1) extract relevant themes from each study, 2) reduce these themes into abstract findings and 3) calculate effect sizes. First, the result sections of the included papers were searched for themes that were stated as criteria for recovery or "being recovered". Themes that were included were: themes that were stated by all participants and themes endorsed by an unknown number of participants, but wherein the theme was part of a main category. For instance, in one study [46], it was unclear how many respondents endorsed on the theme "sense of self-worth", this theme was, however, part of a main category in the results, "discovering and reclaiming self as good enough" and therefore included. Themes that specifically addressed aspects of the process of recovery (i.e. how long it took, development, stages) were excluded, as were themes that were part of the first or initial phases of a recovery process, since we were interested in criteria which are present when people are fully recovered. The themes were identified independently by the first and second author and stored in their original content. To obtain one dataset for the second step (abstract findings), results were first discussed per study for half of the included articles. For the other half of the studies, the data set of the first author was used by the second author to look for further differences in themes. Differences in found statements were discussed until agreement was reached. This resulted in a dataset with 346 statements which was audited by the third and fourth author.In the second step, the reduction into abstract findings, the labels were established. Eating disorder pathology was divided in three sub labels (behavior/cognitions, body evaluation and physical functions). For the additional themes, the well-being dimensions were used since they seem to relate closely to the themes that are described in qualitative research on eating disorder recovery. The following additional labels were used; emotional, psychological and social well-being with their underlying dimensions as stated in earlier work [31, 36, 38]. Also, a "miscellaneous" label was used for criteria that did not fit into one of the other labels. All themes were read carefully by the first two authors to examine whether they could be labeled corresponding the concept labels. Some of the well-being dimensions were very strictly or narrowly described in the literature [31, 37, 38], A minor adjustment in the description of three labels was necessary for the purpose of labeling the themes (see Table 1 for the adjustments). Then, all 346 original themes were labeled separately by the first and fourth author. Inter-rater agreement (kappa coefficient) for the labeling process between the authors was .81 (95\% CI .77-.86) before discussion.

\section{Interpretation of results}

During the discussion, the miscellaneous label could be split into two sub labels (self-management/resilience and spiritual integration). Themes that were part of the discussion were "social contribution" versus "purpose and meaning in life". The theme "Helping others", for instance was sometimes explained as a new purpose for participants, but it is also a form of social contribution. Other things that were discussed were; "Identity integration" as part of "personal growth" or as a separate label, and "self-adaptability/resilience" as a part of "autonomy" or as a separate label. See Table 1 for an overview of the final list regarding the labels and descriptives.In the third step, frequency and intensity effect sizes were calculated for all labels. The frequency effect size shows how frequent labels are mentioned across studies and is 
Table 1 Labels

Health criteria
1. Eating disorder pathology
ED behavior/cognitions
ED body evaluation
ED physical functions
2. Emotional well-being
Avowed happiness
Positive affect
Avowed life satisfaction
3. Psychological well-being
Self-acceptance

Environmental mastery

Positive relationships with others

Personal growth

Autonomy

Purpose in life

4. Social well-being

Social contribution

Social integration

Social actualization

Social acceptance

Social coherence

5. Miscellaneous labels

Self-adaptability/resilience

Spiritual integration
Description

Improvement/absence of ED related behavior (bingeing/purging, slimming,) and cognitions (more relaxed/normal thoughts/affect regarding food/weight/ exercising).

More relaxed regarding body/weight (satisfaction/evaluation).

Improvement in BMI and/or other physical functions.

Feeling happy, feeling joy, enjoyment.

Feeling cheerful, in good spirits, calm, and peaceful, satisfied, and full of life.

Feeling satisfied with life in general or specific areas of one's life.

Holding positive attitudes towards oneself and past life and conceding and accepting varied aspects of self, holding a compassionate attitude towards self. ${ }^{a}$ Having self-respect. Having feelings of self-worth or self-esteem/confidence. Taking self-care.

Exhibiting the capability to manage a complex environment, and the ability to choose or manage and mould environments to one's needs.

Having warm, satisfying, trusting personal relationships and being capable of empathy and intimacy and being open and personal to others.

Showing insight into one's own self and potential, having a sense of development, and being open to new and challenging experiences. ${ }^{a}$ Identity formation/integration: Having a sense of integration of several/all aspects of self and or formation of (healthy/autonomous) aspects of self.

Exhibiting a self-direction that is often guided by one's own socially accepted and conventional internal standards and resisting unsavory social pressures. a Self-determination, independence, and the regulation of behavior from within [81]. Autonomy as used in self-determination theory means acting with the experience of choice [39].

Holding goals and beliefs that affirm one's sense of direction in life and feeling that life had a purpose and meaning.

Feeling that one's own life is useful to society and that the output of one's activities is valued by or valuable to others.

Having a sense of belonging to a community and deriving comfort and support from that community.

Believing that people, social groups, and society have potential and can evolve or grow positively.

Having a positive attitude towards others while acknowledging and accepting people's differences and their complexity.

Being interested in society or social life, and feeling that society and culture are intelligible, somewhat logical, predictable, and meaningful.

Copingstrategies/resilience/empowerment/willpower/persistance/emotionregulation, (Healthy) strategies to cope with emotions and difficult life situations.

Having a sense of being part of, or in contact with a higher power (Universe, God, Jesus, other) and deriving comfort and support from that. Exercises/activities that promote this: meditation, going to Church, praying etc.

Note: well-being descriptions are published earlier in $[29,31],{ }^{a}=$ added descriptions to the original labels

calculated by dividing the number of studies containing the same finding by the total number of studies [60]. Labels were indicated as strong evidence for ED recovery criteria, when they were reported by at least $75 \%$ of the primary studies, as substantial evidence when they were reported by $50 \%$ to $75 \%$ of the primary studies, as moderate evidence when they were reported by $25 \%$ to $50 \%$ of the primary studies, and as insufficient evidence if less than $25 \%$ of the studies reported on a dimension. Although these cut-off points are rather arbitrary, we 
decided to use quartiles as cut off for ease of interpretation and pragmatic value for those seeking evidence on recovery criteria.

The intensity effect size gives a clear measure for how fundamental recovery criteria are compared to each other. The intensity effect size is calculated as the number of findings for a criteria produced in all studies, divided by all findings [60]. To examine possible effects of the methodological quality of the studies on the results, differences in outcomes on the intensity effect size between low risk of bias studies (A/A) and substantial risk for bias studies $(B / B)$ were tested using a proportion significance test ( $\chi^{2}$ test for homogeneity).

\section{Results}

\section{Descriptives}

See Table 2 for an overview of the included studies and quality rating. The 18 included studies covered 286 participants (269 women and 17 men), with an average age of 30.2 years ( $\mathrm{SD}=7.3$ years). One hundred-sixty-three participants had been diagnosed with AN, 25 participants had been diagnosed with Bulimia Nervosa (BN), 18 participants had a history of both $\mathrm{AN}$ and $\mathrm{BN}$ diagnosis over their life course, 8 participants had been diagnosed with Binge Eating Disorders (BED) and 13 participants had been diagnosed with an Eating Disorder Not Otherwise Specified (EDNOS). The average duration of the eating disorder was 8.2 years $(S D=5.1$, study number: $1,3,6,11,16$ ) with a minimum length of 1.5 years and a maximum length of 44 years (study number: $1,6,11,16,17)$. The average length of recovery was 9.1 years $(S D=6.1$ years, study number: $1,3,6,11)$, with a range of 1 year to 35 years (study number: $1,2,6,7,8,11,13,17)$. However, for many studies this was unknown.

\section{Criteria for eating disorder recovery}

See Table 3 for the intensity and frequency effect sizes of the criteria for recovery. The frequency effect sizes show strong evidence for positive relationships with others (100\%), self-acceptance (88.9\%), autonomy (83.3\%), personal growth (77.8\%), improved ED behavior/cognitions (77.8\%), self-adaptability/resilience (77.8\%). Substantial to moderate evidence was found for improved body evaluation $(55.6 \%)$, social contribution (50\%), purpose and meaning in life (38.9\%), spiritual integration (33.3\%), improved (ED) physical functioning (27.8\%) and positive affect (27.8\%). Insufficient evidence was found for happiness $(22.2 \%)$, avowed life satisfaction $(22.2 \%)$, environmental mastery (11.1\%), social acceptance $(11.1 \%)$, social integration $(11.1 \%)$, social actualization $(0 \%)$ and social coherence $(0 \%)$.

Examining the effect sizes of the overall mental health dimensions; psychological well-being accounted for
$52.3 \%$ of all recovery criteria, eating disorder pathology for $20.8 \%$, self-adaptability/resilience and spiritual integration for $13.8 \%$, social well-being for $8.6 \%$ and emotional well-being for $4.6 \%$. Examining the intensity effect sizes of the underlying eating disorder pathology criteria; improved ED behavior/cognitions accounted for $12.4 \%$ of the whole sample, improved body evaluation for $5.8 \%$ and physical improvement for $2.6 \%$. Improved behavior/ cognitions were described in the original studies in several ways. Recurring themes were; returning to a normal eating pattern, no weight phobia, or ending the obsession with weight/food. Physical improvement was primarily about weight recovery and improvement of physical complications.

\section{Testing risk of bias}

Eight studies had an "AA" status and 8 studies a "BB" status. Except for the criteria "personal growth" and "spiritual integration", no differences in proportions of the intensity effect sizes were found between "AA" and "BB" studies (see Table 3). Only two studies had a moderate indication for bias $(\mathrm{A} / \mathrm{B}$, or $\mathrm{B} / \mathrm{A})$ status and could not be used for testing significance because of the low sample size (Fig. 2).

\section{Discussion}

Criteria for recovery were examined using a qualitative meta-analytic approach. Studies were selected that examined the personal experiences of recovered individuals.

\section{Fundamental recovery criteria}

The aim of this study was to identify fundamental criteria for ED recovery according to recovered individuals. Several health dimensions besides symptom remission were found that should be considered as fundamental criteria of eating disorder (ED) recovery. Large frequency effect sizes, indicating strong evidence, were found for the following six criteria: positive relationships with others, self-acceptance, autonomy, personal growth, improved ED behavior/cognitions and self-adaptability/ resilience. Further, substantial to moderate evidence was found for the following six criteria: improved body evaluation, social contribution, purpose and meaning in life, spiritual integration, improved physical functioning and positive affect. At last, insufficient evidence was found for the following seven criteria: happiness, avowed life satisfaction, environmental mastery, social acceptance, social integration, social actualization and social coherence. These results show a clear perspective of the relevant criteria from the perspective of people who have experienced recovery. While remission of ED pathology is considered important, many criteria were about psychological well-being (PWB). Moreover, PWB was 


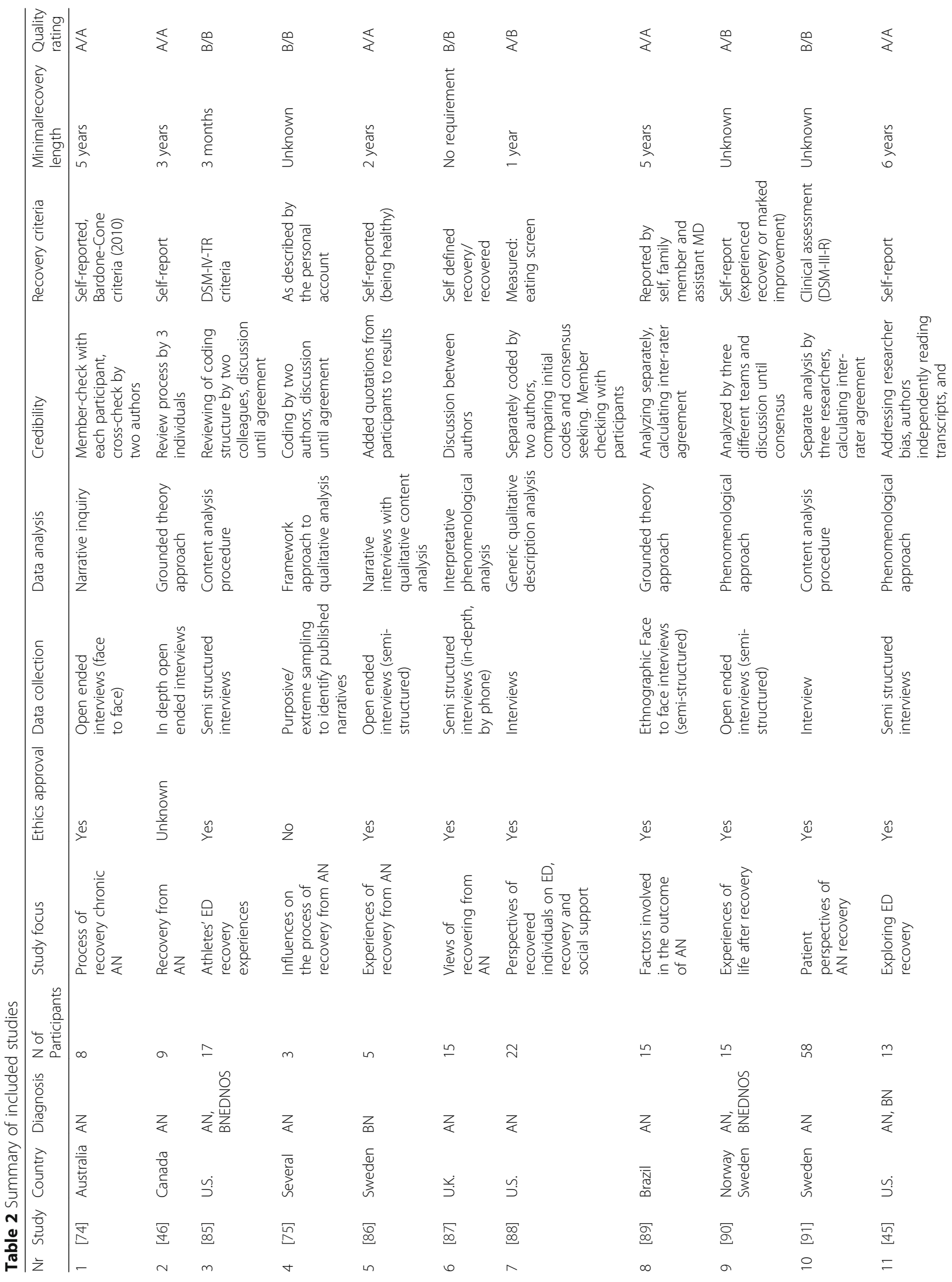


de Vo et al. Journal of Eating Disorders (2017) 5:34

Page 9 of 14

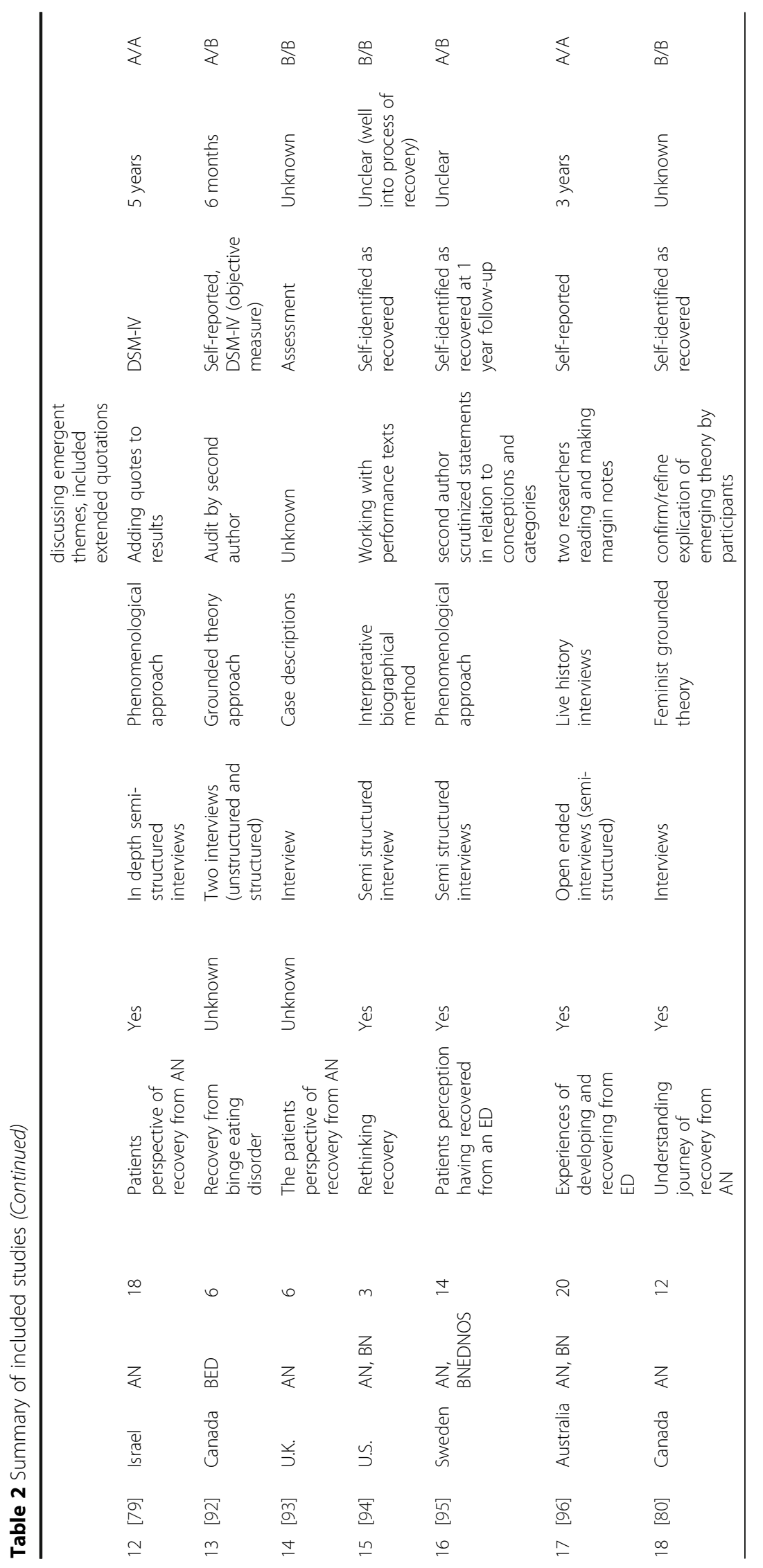


Table 3 Meta-analysis: Intensity and frequency effect sizes of ED recovery criteria

\begin{tabular}{|c|c|c|c|c|c|c|c|}
\hline \multirow[t]{2}{*}{ Recovery Criteria } & \multirow[b]{2}{*}{$\begin{array}{l}\text { Evidence for } \\
\text { recovery }\end{array}$} & \multirow[b]{2}{*}{$\begin{array}{l}\text { Frequency } \\
\text { effect size }\end{array}$} & \multirow{2}{*}{$\begin{array}{l}\text { All }(N=18) \\
\begin{array}{l}\text { Intensity effect } \\
\text { size }\end{array}\end{array}$} & \multirow{2}{*}{$\begin{array}{l}\text { A/A }(N=8) \\
\begin{array}{l}\text { Intensity effect } \\
\text { size }\end{array}\end{array}$} & \multicolumn{3}{|l|}{$\mathrm{B} / \mathrm{B}(\mathrm{N}=8)$} \\
\hline & & & & & $\begin{array}{l}\text { Intensity effect } \\
\text { size }\end{array}$ & $x^{2}$ & $P$ (2-sided) \\
\hline Self-acceptance & Strong & $88.9 \%$ & $15.3 \%$ & $17.6 \%$ & $13.8 \%$ & .679 & .486 \\
\hline $\begin{array}{l}\text { Positive relationsships with } \\
\text { others }\end{array}$ & Strong & $100 \%$ & $12.7 \%$ & $13.4 \%$ & $14.6 \%$ & .070 & .791 \\
\hline Personal growth & Strong & $77.8 \%$ & $12.7 \%$ & $18.5 \%$ & $8.5 \%$ & 5.432 & .020 \\
\hline Decrease in ED behavior/cognitions & Strong & $77.8 \%$ & $12.4 \%$ & $9.2 \%$ & $12.3 \%$ & .603 & .437 \\
\hline Self-adaptability/resilience & Strong & $77.8 \%$ & $9.2 \%$ & $9.2 \%$ & $7.7 \%$ & .082 & .774 \\
\hline Autonomy & Strong & $83.3 \%$ & $7.8 \%$ & $8.4 \%$ & $9.2 \%$ & - & $.791^{*}$ \\
\hline Social contribution & Substantial & $50 \%$ & $6.9 \%$ & $6.7 \%$ & $6.9 \%$ & .004 & .950 \\
\hline Improved (ED) body evaluation & Substantial & $55.6 \%$ & $5.8 \%$ & $1.7 \%$ & $6.2 \%$ & & \\
\hline Spiritual integration & Moderate & $33.3 \%$ & $2.9 \%$ & $.8 \%$ & $6.2 \%$ & - & $.037^{*}$ \\
\hline Purpose \& meaning & Moderate & $38.9 \%$ & $2.9 \%$ & $3.4 \%$ & $3.1 \%$ & .016 & .899 \\
\hline Improved (ED) physical functioning & Moderate & $27.8 \%$ & $2.6 \%$ & $4.2 \%$ & $1.5 \%$ & - & $.264^{*}$ \\
\hline Happiness & Insufficient & $22.2 \%$ & $1.7 \%$ & $.8 \%$ & $1.5 \%$ & - & $1.000^{*}$ \\
\hline Positive affect & Moderate & $27.8 \%$ & $1.7 \%$ & $2.5 \%$ & $.8 \%$ & - & $.351^{*}$ \\
\hline Other & - & $33.3 \%$ & $1.7 \%$ & $.8 \%$ & $2.3 \%$ & - & $.623^{*}$ \\
\hline Avowed life satisfaction & Insufficient & $22.2 \%$ & $1.2 \%$ & $.8 \%$ & $.8 \%$ & - & $1.000^{*}$ \\
\hline Environmental mastery & Insufficient & $11.1 \%$ & $.9 \%$ & $.8 \%$ & $1.5 \%$ & - & $1.000^{*}$ \\
\hline Social acceptance & Insufficient & $11.1 \%$ & $.9 \%$ & - & $2.3 \%$ & & $.247^{*}$ \\
\hline Social integration & Insufficient & $11.1 \%$ & $.9 \%$ & $.8 \%$ & $.8 \%$ & & $1.000^{*}$ \\
\hline Social actualization & Insufficient & - & - & - & - & - & - \\
\hline Social coherence & Insufficient & - - & - & - & - & - & - \\
\hline
\end{tabular}

Note: Frequency effect size: Total $N$ of studies divided by $N$ of studies containing a criteria * 100 , Intensity effect size: $N$ of found criteria produced in all studies, divided by all found criteria in all studies $* 100, x^{2}$ test of homogeneity (differences in two proportions), ${ }^{*} p$ was calculated by Fisher's Exact test for violation of the minimal sample size of the $x^{2}$ test

mentioned more $(52.3 \%$ of all criteria) than the remission of ED pathology (20.8\% of all criteria) as a marker for recovery.

These results underscore the conclusions of earlier work about the importance of including psychological dimensions in definitions of ED recovery [17, 26, 61]. PWB is not about happiness or positive affect, but explained as living a good life, with purpose and meaning, growing towards optimal functioning and self-realization [39, 62]. The philosophical roots of PWB lead back to Aristotle's formulation about the virtues life. The essence of this Greek philosophy is to know yourself and to become what you are [62]. Many themes in the studies were about finding a new or 'healthy' identity and developing self-insight and self-acceptance. Our results suggest that the underlying dimensions of PWB should be considered as fundamental aspects of ED recovery, perhaps even important to focus on during treatment than the abatement of symptoms. A focus on well-being in treatment has been suggested earlier for other psychiatric disorders by Fava and others [32, 41]. It is noted that Parloff and colleagues already suggested in 1954 that the goals of psychotherapy were not necessarily the reduction of symptoms, but increased personal effectiveness [32]. Several therapies have been developed focusing on PWB [63-68]. PWB is further related to work productivity, physical and overall mental health, and care consumption, even when controlling for symptoms of mental illness [37, 69, 70]. It can also improve the quality of life for psychiatric patients, and the change to recover on symptoms and decrease the risk of relapse $[69,71]$.

Environmental mastery was the only PWB dimension that showed insufficient evidence. However, environmental mastery could be considered to be an aspect of self-adaptability. Self-adaptability is defined broader, taking social and emotional adaptability into account. If the description of environmental mastery was described more broadly, taking all aspects of self-adaptability into account, this probably would have been found as evidence for a criterion for ED recovery. Limitations in the first WHO definition of health have recently led to a new definition of health, described as the ability to adapt and to self-manage, in the face of social, physical and emotional challenges [72, 73]. The importance of self- 


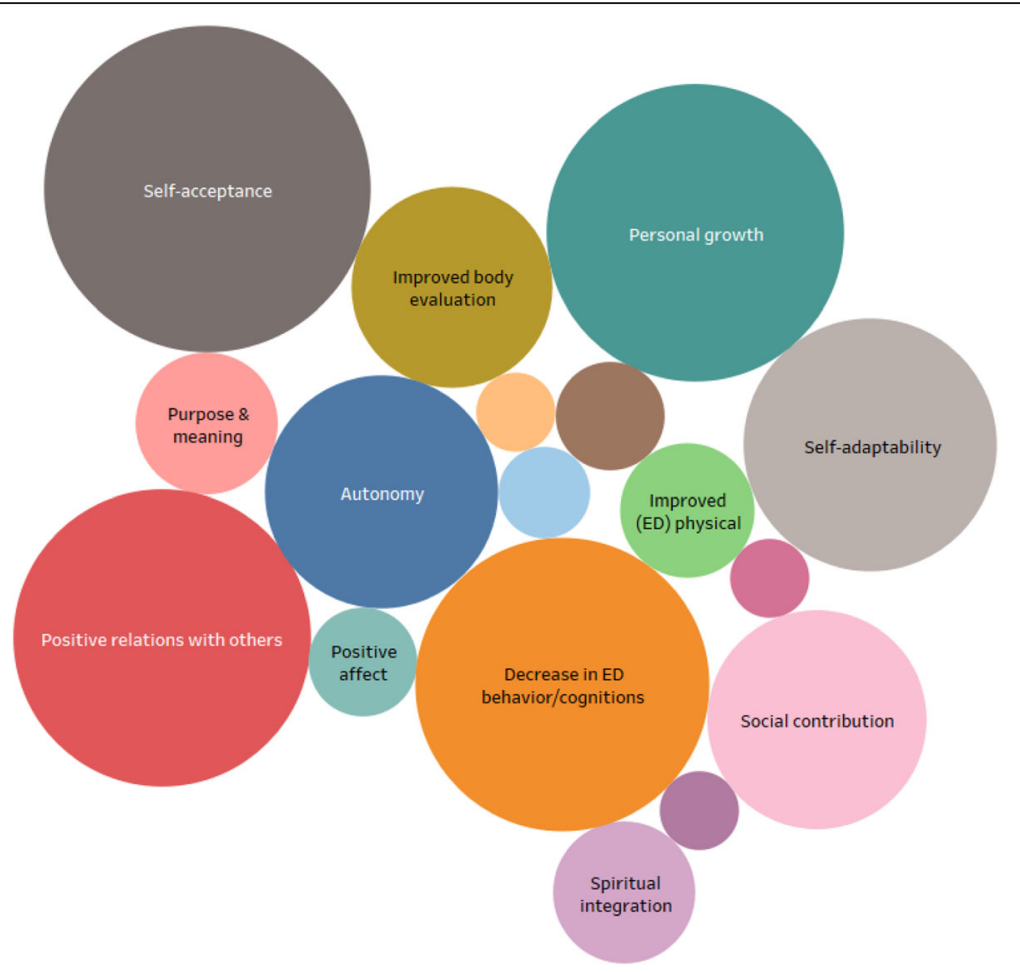

Fig. 2 Intensity effect sizes of criteria for recovery. Circles represent criteria for recovery and are based on the intensity effectsizes. The larger the circle, the larger the intensity effectsize. Circles that are labeled with a text have moderate, substantial or strong evidence for a recovery criteria. Circles that are not labeled with a text are the remaining criteria

adaptability/resilience as a criterion for ED recovery, fits this recently proposed definition of health [73]. In addition, Ryff stated that PWB is fundamentally anchored in how individuals face the challenges of life [62]. It is noted that "being recovered" is certainly not achieving a perfect state on the found criteria. It is explained as a unique and self-determined process by recovered individuals, without a clear endpoint [46, 74-79]. A new definition for ED recovery based on the latest definition of health and the results of this study could be: recovery from an ED is the ability to adapt and to self-manage in the face of social, physical and emotional challenges with an overall tendency towards growth in psychological well-being and adequate symptom remission (for instance as operationalized by Bardone-Cone et al. [18]). ED patients reported an overall impairment in PWB in a controlled study, which was not necessarily dependent on the presence of high levels of symptom severity, suggesting that PWB does not simply correspond to the absence of pathology [42]. Well-being and pathology as two different but related aspects of health has been well validated in several samples of the normal population and in patients $[31,36,41]$.

"Recovery" may also indicate both a process and a state [32]. For eating disorder recovery, criteria also occupy a tenuous place between facilitators of recovery and criteria for demonstrating recovery in the literature. It is not always clear whether these themes are offered as requirements for ascertaining the degree to which someone is recovered or as facilitators to achieve recovery. In outcome studies, most themes, from changes in BMI to improvement in self-esteem, are used both as predictor variables and outcome variables; see for instance Vall and Wade [21]. One of the conclusions of a recent meta-synthesis was that the presence of supportive relationships is an important facilitator for recovery [47]. Recovery in the qualitative sense is often described as a process or journey [74, 75,80$]$; and yet, what we need in a clinical sense is criteria to gauge and compare outcomes (see also Rosenvinge and Pettersen [17], p. 1). We argue that recovery dimensions that remain important aspects for individuals' health, such as positive relationships, are operationalized as criteria for recovery, in accordance with health and well-being definitions [37, 81]. It is likely that these criteria, related to well-being, are also important as criteria for recovery for other pychiatric disorders, such as depression. In a sample of patients with depressive symptoms, it was found that not only psychopathology improves, but also that PWB increases during treatment [82]. In another outcome study it was found that many patients with depressive symptoms improved either on psychopathology, or on 
the well-being dimensions and not on both, suggesting that both are important to measure in outcome studies and should be considered as criteria for recovery for psychiatric disorders [83].

\section{Limitations}

Although a qualitative meta-analytic approach allows for a more comprehensive explanation of a phenomenon than the individual qualitative studies explain, there are several limitations concerning this study. First, the presented methods and results were influenced by the methodology of the primary studies and their findings. Some of the primary studies failed to provide sufficient details about the background of the participants, used methods and/or results. It is also unclear how different systems of data analysis have formed the results in the primary studies. By examining differences in outcomes between low risk of bias studies and risk of bias studies we tried to minimize the risk of bias. Second, that some hypothesized dimensions were or were not supported does not necessarily depend only on the studies and participants, but also may be a flaw in inadequate thematic analysis or misclassification of themes. We tried to address possible classification bias by independent analysis and calculating an interrater agreement. Third, this study shows frequencies, constituting the importance of recovery criteria, but fails to show the contradictions between studies, including, but not least, that to claim that those in the study were recovered, they had to determine provisional criteria for recovery, which differed significantly between studies. The method of this study did not allow to examine differences in criteria between type of eating disorder. Most primary studies focused on either, AN, or all eating disorder types, which makes it difficult to divide results into ED type groups. Further research could focus on differences in well-being criteria between ED types. In a study examining the dimensions of psychological well-being among ED patients, differences in severity were found [42]. Compared with a control group, patients with BN had greater impairment on all psychological well-being scales, whereas patients with BED showed greater impairment on only three scales and patients with AN on only two scales. It is possible that improvement on the several well-being dimensions has a different priority depending on the ED type [42]. Also, the search strategy was quite narrow, with a lack of synonyms for "recovery" or "recovered", such as "remission", "rehabilitation", "restoration". However, we argue that these synonyms are not used regularly in qualitative ED recovery studies examining the view of patients or recovered individuals. In fact, in the reference-check, no suitable other studies were found using these synonyms. At last, this study examined criteria for being recovered among people who were considered recovered. Further research should examine how these recovery criteria develop and influence each other during the recovery process.

\section{Conclusions}

We conclude that psychological well-being and selfadaptability are core aspects of recovery in addition to remission of ED symptoms. A focus in treatment on these health dimensions seems therefore important to achieve recovery. Whether someone is recovered or not remains a question primarily to be answered by the patient her/himself. However, to find best treatment options, researchers and clinicians need to measure the most fundamental criteria for recovery. This study, among other studies $[16,17,25,26,47,84]$, provides a further direction to understand which criteria are most important to measure. Developing and validating instruments that measure recovery on these fundamental criteria is warranted. It is also advised to establish an international standard or guideline on how to measure ED recovery outcomes and which instruments to use, so that we might be able to compare treatment outcomes in the near future.

\section{Abbreviations \\ AN: Anorexia Nervosa; BED: Binge Eating Disorder; BN: Bulimia Nervosa; ED: Eating Disorder; EDNOS: Eating Disorder Not Otherwise Specified; PWB: Psychological Well-being}

\section{Acknowledgements \\ The authors would like to thank Beth McGilley for her excellent comments on the manuscript. \\ Funding \\ The authors do not have any funds available for this study. \\ Availability of data and materials \\ The data is available in the selected studies. The dataset that was generated after extracting the themes from the selected studies is available upon a} substantiated request to the corresponding author.

\section{Authors' contributions}

The contributions of the authors were as follows: ETB rewrote the introduction, results and discussion and commented on all versions of the manuscript. GJW, wrote several parts of the introduction, audited the analysis, and commented on all versions of the manuscript. MR wrote parts in the introduction and discussion, improved the procedure of the analysis, audited the analysis, and commented on all versions of the manuscript. CAB analysed the data by labeling the original themes and commented on one version of the manuscript. ALM wrote several parts of the introduction, searched for eligible studies, helped with the analysis, and commented on several versions of the manuscript. JAV selected the articles from the databases, searched for eligible studies, analysed the data by labeling the original themes, did the significance tests, and wrote most parts of the manuscript and tables. All authors read and approved the final manuscript.

\section{Ethics approval and consent to participate}

Not applicable.

\section{Consent for publication}

All authors read and approved the final manuscript and consented for publication.

\section{Competing interests}

The authors declare that they have no competing interests. 


\section{Publisher's Note}

Springer Nature remains neutral with regard to jurisdictional claims in published maps and institutional affiliations.

\begin{abstract}
Author details
'Centre for eHealth and Well-being Research, University of Twente, Psychology, Health, \& Technology, Enschede, The Netherlands. ${ }^{2}$ Human Concern Foundation, center for Eating Disorders, Amsterdam, The Netherlands. ${ }^{3}$ University of Guelph, Department of Family Relations and Applied Nutrition, Ontario, Canada. ${ }^{4}$ Optentia Research Focus Area, North-West University (VTC), Vanderbijlpark, South Africa.
\end{abstract}

Received: 6 April 2017 Accepted: 29 June 2017

Published online: 01 November 2017

\section{References}

1. Jenkins HRR, Meyer C, Blissett JM. Eating disorders and quality of life: a review of the literature. Clin Psychol Rev. 2011;31:113-21.

2. Mitchison D, Hay PJ, Slewa-Younan S, Mond J. Time trends in population prevalence of eating disorder behaviors and their relationship to quality of life. PLoS One. 2012;7:e48450

3. Mond J, Hay PJ, Rodgers B, Owen C. Quality of life impairment in a community sample of women with eating disorders. Aust N Z J Psychiatry. 2012;46:561-8.

4. Hoek HW. Incidence, prevalence and mortality of anorexia nervosa and other eating disorders. Curr Opin Psychiatry. 2006;19:389-94.

5. Harris EC, Barraclough B. Excess mortality of mental disorder. Br J Psychiatry. 1998:173:11-53.

6. Löwe B, Zipfel S, Buchholz C, Dupont Y, Reas DL, Herzog W. Long-term outcome of anorexia nervosa in a prospective 21-year follow-up study. Psychol Med. 2001;31:881-90.

7. Hay PJ, Chinn D, Forbes D, Madden S, Newton R, Sugenor L, et al. Royal Australian and new Zealand College of Psychiatrists clinical practice guidelines for the treatment of eating disorders. Aust New Zeal J Psychiatry. 2014;48:1-62.

8. Trimbos: Multidisciplinaire richtlijn eetstoornissen: richtlijn voor de diagnostiek en behandeling van eetstoornissen [Multidisciplinary quideline for diagnostics and treatment of eating disorders] [Internet]. Utrecht: Trimbos Instituut; 2006. Available from: www.ggzrichtlijnen.nl/ eetstoornissen.

9. Yager J, Devlin MJ, Halmi KA, Herzog DB, lii JEM, Powers P, et al. Treatment of patients with eating disorders, third edition work group on eating disorders guide to using this practice guideline introduction 2006;

10. Bulik CM, Berkman ND, Brownley KA, Sedway JA, Lohr KN. Anorexia nervosa treatment: a systematic review of randomized controlled trials. Int J Eat Disord. 2007:40:310-20.

11. Hay PJ. A systematic review of evidence for psychological treatments in eating disorders: 2005-2012. Int J Eat Disord. 2013:46:462-9.

12. Zipfel S, Giel KE, Bulik CM, Hay P, Schmidt U. Anorexia nervosa: aetiology, assessment, and treatment. The lancet Psychiatry. 2015;2:1099-111.

13. Berkman ND, Lohr KN, Bulik CM. Outcomes of eating disorders: a systematic review of the literature. Int J Eat Disord. 2007:40:293-309.

14. Noordenbos $\mathrm{G}$. When have eating disordered patients recovered and what do the DSM-IV criteria tell about recovery? Eat Disord J Treat Prev. 201 1;19:234-45.

15. McGilley BH, Szablewski JK. Chapter 12 - recipe for recovery: necessary ingredients for the Client's and Clinician's success. In: Maine M, McGilley BH, Bunnell DW, editors. Treatment of eating disorders. San Diego: Academic Press; 2010. p. 197-213.

16. Jarman $\mathrm{M}$, Walsh $\mathrm{S}$. Evaluating recovery from anorexia nervosa and bulimia nervosa: integrating lessons learned from research and clinical practice. Clin Psychol Rev. 1999;19:773-88.

17. Rosenvinge JH, Pettersen G: Relevant topics in eating disorders; in Lobera IJ (ed). InTech, 2012.

18. Bardone-Cone AM, Harney MB, Maldonado CR, Lawson MA, Robinson P, Smith $R$, et al. Defining recovery from an eating disorder: conceptualization, validation, and examination of psychosocial functioning and psychiatric comorbidity. Behav Res Ther. 2010;48:194-202.

19. Couturier J, Lock J. What is recovery in adolescents anorexia nervosa? Int Eat Disord. 2006;39:550-5.

20. Steinhausen HC. The outcome of anorexia nervosa in the 20th century. Am J Psychiatry. 2002;159:1284-93.
21. Vall E, Wade TD. Predictors of treatment outcome in individuals with eating disorders: a systematic review and meta-analysis. Int J Eat Disord. 2015:48:946-71.

22. Fairburn CG, Beglin S. Assessment of eating disorders: interview or self-report questionnaire? Int J Eat Disord. 1994;16:363-70.

23. de la Rie SM, Noordenbos G, van Furth EF. Quality of life and eating disorders. Qual Life Res. 2005:14:1511-22.

24. Dawson L, Rhodes P, Touyz S. Defining recovery from anorexia nervosa: a Delphi study to explore practitioners' views. J Eat Disord. 2015; doi:10.1080/ 21662630.2015.1009145.

25. Noordenbos G, Seubring A. Criteria for recovery from eating disorders according to patients and therapists. Eat Disord. 2006;14:41-54.

26. Emanuelli $P$, Waller $G$, Jones-Chester M, Ostuzzi R. Recovery from disordered eating: sufferers' and clinicians' perspectives. Eur Eat Disord Rev. 2012;20:363-72

27. Keyes CLM. The mental health continuum: from languishing to flourishing in life. J Health Soc Behav. 2002;43:207-22.

28. Jahoda M. Current concepts of positive mental health. Joint commission on mental health and illness monograph series. Vol 1. New York, US: Basic Books; 1958. p. xxi.

29. Westerhof GJ, Keyes CLM. Mental illness and mental health: the two continua model across the lifespan. J Adult Dev. 2010;17:110-9.

30. Seligman M, Csikszentmihalyi M. Positive psychology: an introduction. Am Psychol. 2000;55:5-14.

31. Lamers SMA. Positive mental health : measurement, relevance and implications; 2012. doi:10.3990/1.9789036533706.

32. Fava GA. The concept of recovery in affective disorders. Psychother Psychosom. 1996;65:2-13.

33. Fava GA, Ruini C. Development and characteristics of a well-being enhancing psychotherapeutic strategy: well-being therapy. J Behav Ther Exp Psychiatry. 2003;34:45-63.

34. Ryff CD, Singer B. Psychological well-being: meaning, measurement, and implications for psychotherapy research. Psychother Psychosom. 1996;65:14-23.

35. World Health Organization. Promoting mental health: concepts, emerging evidence, practice. Geneva: WHO; 2005.

36. Keyes CLM. Mental illness and/or mental health? Investigating axioms of the complete state model of health. J Consult Clin Psychol. 2005;73

37. Keyes CLM. Mental illness and/or mental health? Investigating axioms of the complete state model of health. J Consult Clin Psychol. 2005;73:539-48.

38. Ryff C. Happiness is everything, or is it? Explorations on the meaning of psychological well-being. J Pers Soc Psychol. 1989;57:1069-81.

39. Deci EL, Ryan RM. Hedonia, eudaimonia, and well-being: an introduction. [Internet]. J Happiness Stud. 2008;9:1-11.

40. Lamers SMA, Westerhof GJ, Bohlmeijer ET, CLM K. Mental health and illness in relation to physical health across the lifespan. New York: Springer; 2013.

41. Lamers SMA, Westerhof GJ, Glas C a. W, Bohlmeijer ET: the bidirectional relation between positive mental health and psychopathology in a longitudinal representative panel study. J Posit Psychol 2015;9760:1-8.

42. Tomba E, Offidani E, Tecuta L, Schumann R, Ballardini D. Psychological wellbeing in out-patients with eating disorders: a controlled study. Int J Eat Disord. 2014:47:252-8.

43. Doll HA, Petersen SE, Stewart-brown SL. Eating disorders and emotional and physical well-being: associations between student self-reports of eating disorders and quality of life as measured by the SF-36. Qual Life Res. 2005;14:705-17.

44. de la Rie SM, Noordenbos G, Donker M, van Furth E. The patient's view on quality of life and eating disorders. Int J Eat Disord. 2007:40:13-20.

45. Bowlby CCG, Anderson TTL, Hall MEL, Willingham MMM, Lewis Hall M, Willingham MMM. Recovered professionals exploring eating disorder recovery: a qualitative investigation of meaning. Clin Soc Work J. 2012:43:1-10

46. Lamoureux MMH, Bottorff JL. "Becoming the real me": recovering from anorexia nervosa. Health Care Women Int. 2005;26:170-88.

47. Duncan TK, Sebar B, Lee J. Reclamation of power and self: a meta-synthesis exploring the process of recovery from anorexia nervosa. Adv Eat Disord Theory Res Pract. 2015:3:177-90.

48. Leslie J: Understanding the changing landscape of client perspectives of recovery from anorexia nervosa. 2014

49. Shohet M. Narrating anorexia: "full" and "struggling" genres of recovery. Ethos. 2007:35:344-82.

50. Timulak L. Meta-analysis of qualitative studies : a tool for reviewing qualitative research findings in psychotherapy. Psychother Res. 2009;19:591-600, 
51. Schreiber R, Crooks D, Stern PN. Qualitative meta-analysis. In: Morse JM, editor. Completing a qualitative project: details and dialogue. CA, Sage: Thousand Oaks; 1997. p. 311-26.

52. Finfgeld DL. Metasynthesis: the state of the art-so far. Qual Health Res. 2003;13:893-904.

53. Liberati A, Altman DG, Tetzlaff J, Mulrow C, JPA I, Clarke M, et al. Annals of internal medicine academia and clinic the PRISMA statement for reporting systematic reviews and meta-analyses of studies that evaluate health care Interventions. Ann Intern Med. 2009;151:W65-94.

54. American Psychiatric Association: Diagnostics and statistical manual of mental disorders (5th ed.). Washington DC: APA; 2013.

55. Barroso J, Powell-Cope GM. Metasynthesis of qualitative research on living with HIV infection. Qual Health Res. 2000;10:340-53.

56. Critical Appraisal Skills Programme (CASP): Qualitative Research Checklist: 10 questions to help you make sense of qualitative research [Internet]. Oxford: Better Value Healthcare; 2013. Available from: www.casp-uk.net.

57. Espindola CR, Blay SL. Anorexia nervosa treatment from the patient perspective: a metasynthesis of qualitative studies. Ann Clin Psychiatry. 2009;21:38-48

58. Feder GS, Hutson M, Ramsay J, Taket AR. Women exposed to intimate partner violence: expectations and experiences when they encounter health care professionals: a meta-analysis of qualitative studies. Arch Intern Med. 2006;166:22-37.

59. Campbell R, Pound P, Pope C, Britten N, Pill R, Morgan M, et al. Evaluating meta- ethnography: a synthesis of qualitative research on lay experiences of diabetes and diabetes care. Soc Sci Med. 2003;54:671-84.

60. Sandelowski M, Barroso J. Creating metasummaries of qualitative findings. Nurs Res. 2003:52:226-33.

61. Noordenbos G. Which criteria for recovery are relevant according to eating disorder patients and therapists? Eat Disord J Treat Prev. 2011;19:441-51.

62. Ryff CD. Psychological well-being revisited: advances in the science and practice of Eudaimonia. Psychother Psychosom. 2014;83:10-28.

63. Fava GA, Rafanelli C, Cazzaro M, Conti S, Grandi S. Well-being therapy. A novel psychotherapeutic approach for residual symptoms of affective disorders. Psychol Med. 1998;28:475-80.

64. Weiss LA, Westerhof GJ, Bohlmeijer ET. Can we increase psychological wellbeing? The effects of interventions on psychological well-being: a metaanalysis of randomized controlled trials. PLoS One. 2016;11:1-16.

65. Weiss LA, Westerhof GJ, Bohlmeijer ET. Nudging socially isolated people towards well-being with the "happiness route": design of a randomized controlled trial for the evaluation of a happiness-based intervention. Health Qual Life Outcomes. 2013;11:159.

66. Fava GA, Ruini C, Rafanelli C, Finos L, Salmaso L, Mangelli L, et al. Well-being therapy of generalized anxiety disorder. Psychother Psychosom. 2005;74:26-30.

67. Gander F, Proyer RT, Ruch W. Positive psychology interventions addressing pleasure, engagement, meaning, positive relationships, and accomplishment increase well-being and ameliorate depressive symptoms: a randomized, placebo-controlled online study. Front Psychol. 2016;7 doi:10. 3389/fpsyg.2016.00686.

68. Fava GA, Tomba E. Increasing psychological well-being and resilience by psychotherapeutic methods. J Pers. 2009;77:1903-34.

69. Weiss LA. Direction: happiness. Improving well-being of vulnerable groups. Enschede, the Netherlands: University of Twente; 2016.

70. Chida Y, Steptoe A. Positive psychological well-being and mortality: a quantitative review of prospective observational studies. Psychosom Med. 2008;70(7):741-56.

71. Sin N, Della Porta M, Lyubomirsky S. Tailoring positive psychology interventions to treat depressed individuals. In: Donaldson S, Csikszentmihalyi M, Nakamura J, editors. Applied positive psychology: improving everyday life, health, schools, work, and society; 2011. p. 79-96.

72. Huber M, van Vliet M, Giezenberg M, Winkens B, Heerkens Y, Dagnelie PC, et al. Towards a "patient-centred" operationalisation of the new dynamic concept of health: a mixed methods study. BMJ Open. 2016;6:e010091.

73. Huber M, Knottnerus JA, Green L, Horst HVD, Jadad AR, Kromhout D, et al. How should we define health? Br Med J. 2011;343:1-3.

74. Dawson L, Rhodes P, Touyz S. "doing the impossible": the process of recovery from chronic anorexia nervosa. Qual Health Res. 2014:24:494-505.

75. Hay PJ, Cho K. A qualitative exploration of influences on the process of recovery from personal written accounts of people with anorexia nervosa. Women Health. 2013;53:730-40.
76. Lindgren B-M, Enmark A, Bohman A, Lundstrom M. A qualitative study of young women's experiences of recovery from bulimia nervosa. J Adv Nurs. 2015;71:860-9.

77. Jenkins J, Ogden J. Becoming "whole" again: a qualitative study of women's views of recovering from anorexia nervosa; 2012. p. 1-25.

78. Nilsson K, Hägglöf B. Patient perspectives of recovery in adolescent onset anorexia nervosa. Eat Disord. 2006;14:305-11.

79. Shahar M, Latzer $Y$, Buchbinder E. Recovery from anorexia nervosa: the patient's perspective. In: Stein D, Latzer $Y$, Stein D, editors. Latzer $Y$ (Ed) (eds): treatment and recovery of eating disorders. Shahar: Meirav, Nova Science Publishers; 2012. p. 171-85.

80. Weaver K, Wuest J, Ciliska D. Understanding Women's journey of recovering from anorexia nervosa. Qual Health Res. 2005 Feb;15:188-206.

81. Ryff C, Keyes CLM. The structure of psychological well-being revisited. J Pers Soc Psychol. 1995;69(4):719-27.

82. Bohlmeijer ET, Lamers SMA, Fledderus M. Flourishing in people with depressive symptomatology increases withacceptance and commitment therapy. Post-hoc analyses of a randomized controlled trial. Behav Res Ther. 2015;65:101-6.

83. Trompetter HR, Lamers SMA, Westerhof GJ, Fledderus M, Bohlmeijer ET. Both positive mental health and psychopathology should be monitored in psychotherapy: confirmation for the dual-factor model in acceptance and commitment therapy. Behav Res Ther. 2017;91:58-63.

84. Dawson L, Rhodes P, Touyz S. Defining recovery from anorexia nervosa: a Delphi study to determine expert practitioners' views. Adv Eat Disord Theory Res Pract. 2015; doi:10.1080/21662630.2015.1009145.

85. Arthur-Cameselle JNJ. Quatromoni P a: eating disorders in collegiate female athletes: Factors that assist recovery. Eat Disord. 2014;22:50-61.

86. Lindgren B-M, Enmark A, Bohman A, Lundström M. A qualitative study of young women's experiences of recovery from bulimia nervosa. J Adv Nurs. 2015;71:860-9.

87. Jenkins J, Ogden J. Becoming "whole" again: a qualitative study of women's views of recovering from anorexia nervosa. Eur Eat Disord Rev. 2012;20:e23-31.

88. Linville D, Brown T, Sturm K, McDougal T. Eating disorders and social support: perspectives of recovered individuals. Eat Disord. 2012;20:216-31.

89. Espíndola CR, Blay SL. Long term remission of anorexia nervosa: Factors involved in the outcome of female patients. PLoS One. 2013;8:e56275.

90. Björk T, Wallin K, Pettersen G. Male experiences of life after recovery from an eating disorder. Eat Disord. 2012;20:460-8.

91. Nilsson K, Hagglof B. Patient perspectives of recovery in adolescent onset anorexia nervosa. Eat Disord. 2006;14:305-11.

92. Krentz A, Chew J, Arthur N. Recovery from binge eating disorder. Can J Couns. 2005;39:118-35.

93. Hsu GLK, Crisp AH, Callender JS. Recovery in anorexia nervosa - the Patient's perspective. Int J. 1992;11:341-50.

94. Matusek JA, Knudson RM. Rethinking recovery from eating disorders: spiritual and political dimensions. Qual Health Res. 2009;19:697-707.

95. Björk T, Ahlström $\mathrm{G}$. The patient's perception of having recovered from an eating disorder. Health Care Women Int. 2008;29:926-44.

96. Patching J, Lawler J. Understanding women's experiences of developing an eating disorder and recovering: a life-history approach. Nurs Inq. 2009;16(1):10-21.

\section{Submit your next manuscript to BioMed Central and we will help you at every step:}

- We accept pre-submission inquiries

- Our selector tool helps you to find the most relevant journal

- We provide round the clock customer support

- Convenient online submission

- Thorough peer review

- Inclusion in PubMed and all major indexing services

- Maximum visibility for your research

Submit your manuscript at www.biomedcentral.com/submit 